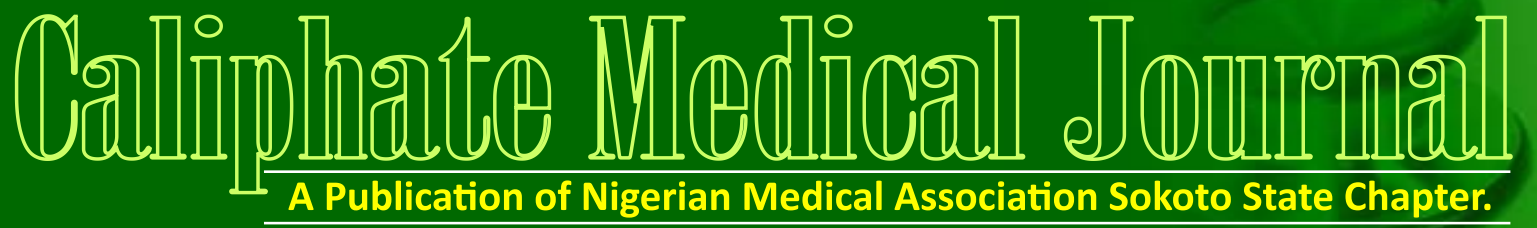

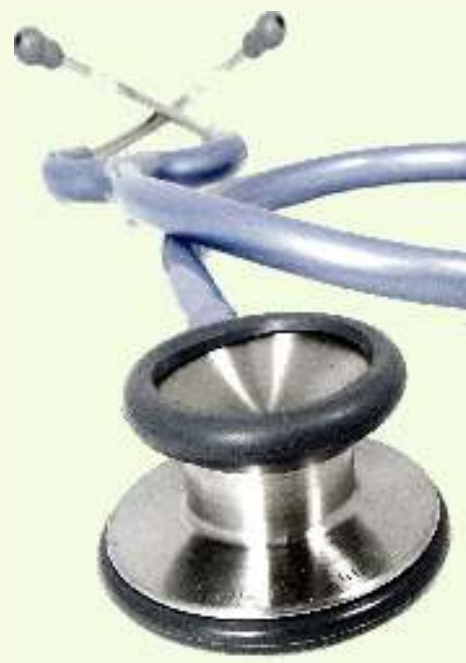

In this Issue

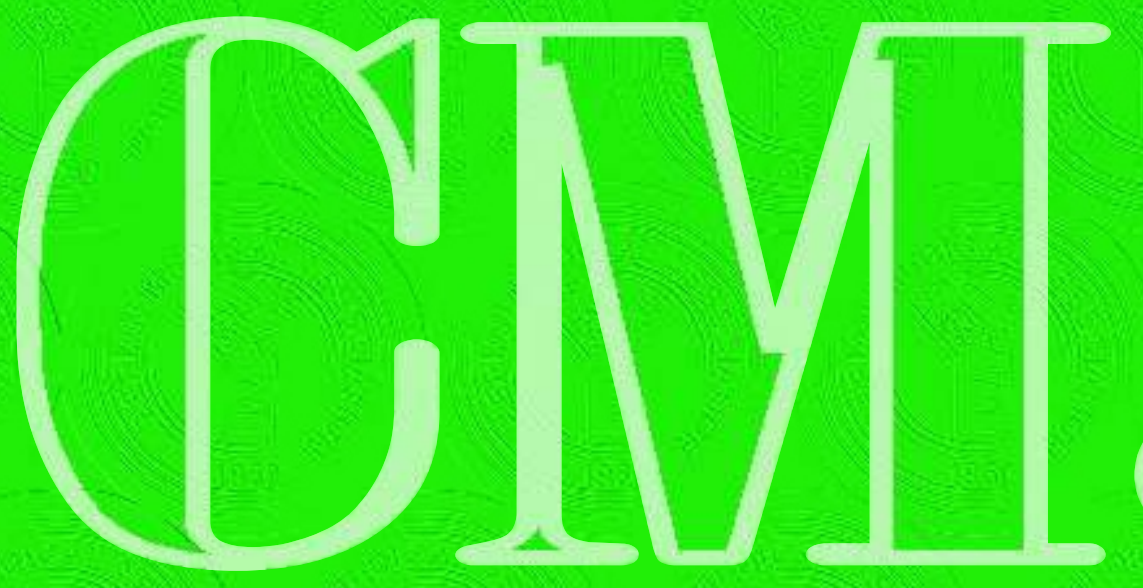




\section{PAEDIATRIC ACUTE PERITONEAL DIALYSIS IN SOKOTO: REVIEW AND OUTCOME}

Ibitoye $\mathbf{P K}^{1}$ and Jiya FB $^{1}$

${ }^{1}$ Department of Paediatrics, Usmanu Danfodiyo University Teaching Hospital, Sokoto, Nigeria

\section{Corresponding author: Dr Paul Kehinde Ibitoye, Department of Paediatrics, Usmanu Danfodiyo University Teaching Hospital, Sokoto, Nigeria, Email: paulsokoto@yahoo.com. Tel: +2348035813643}

\begin{abstract}
Background: Renal replacement therapy (RRT) in form of peritoneal dialysis (PD) is an important treatment procedure in Paediatric Acute Kidney Injury (AKI) management. It is cost effective and materials are easily sourced for in the developing countries. There is paucity of sub-Saharan Africa data on the use of PD in paediatric AKI, hence this study.

Methods: This was a retrospective and descriptive study of cohort of children who were admitted into Emergency Paediatrics Unit of Department of Paediatrics, Usmanu Danfodiyo University Teaching Hospital, Sokoto, and had PD done between July $1^{\text {st }}, 2007$ and July $31^{\text {st }}, 2019$. Age, gender, cause of AKI, indication for dialysis, type of dialysis fluid and peritoneal access used, duration, complication and outcome were documented.
\end{abstract}

Results: A total number of 11 children who had acute PD due to AKI during the duration were studied with male preponderance of $8(72.7 \%)$ and majority $(81.8 \%)$ belonging to lower social class (IV and V). Their ages ranged between 5 months and 12 years with a mean age of $4.8 \pm 3$ years. Acute glomerulonephritis (AGN) $(n=5)$, severe acute diarrhoeal disease $(n=4)$ and obstructive nephropathy $(n=2)$ were causes of AKI. Peritoneal dialysis was performed manually using percutaneous commercial PD catheters $(n=10)$ and adapted catheter $(n=1)$. Duration of PD ranged from 3 to 17 days (mean: $8.1 \pm 4.1$ days). The main complications were peri-catheter leakage $(n=6)$, and catheter obstruction $(n=3)$, exit wound $(n=2)$ and acute bacterial peritonitis $(n=1)$. Of the 11 patients, 7 $(63.6 \%)$ were discharged home alive and well, $3(27.4 \%)$ died and $1(9.1 \%)$ left against medical advice.

Conclusion: With meticulous attention to aseptic procedure and use of improvised dialysis fluids and catheters or semi-rigid PD catheters where available, PD is an affordable choice of RRT in management of paediatric AKI Complications are bound to occur and are better anticipated and planned for

KEY WORDS: Acute Peritoneal Dialysis, Acute Kidney Injury, Outcome, Sokoto

\section{Introduction}

$\mathbf{P}$ eritoneal dialysis was the first renal replacement therapy (RRT) modality and in children, it is preferred in the management of Acute Kidney Injury (AKI). ${ }^{1}$ Two major forms of RRT are available in the management of AKI in children; intermittent haemodialysis (HD) which needs haemodynamic stability for its use and peritoneal dialysis (PD). The third technique in form of continuous RRT is for acute dialysis in the intensive care setting and can be used in haemodynamically unstable patients.

In developing countries associated with poor-resource setting, peritoneal dialysis is most practised in children because it is cost effective and some PD items can be improvised especially catheter and dialysate fluids. ${ }^{3-8}$ This is unlike intermittent haemodialysis which is expensive and items needed not easily available in sub-Saharan Africa. More so, the technique of intermittent haemodialysis is quite sophisticated and somewhat difficult to manage in children in most health facilities in subSaharan Africa.

The most common indications for acute PD in children are complications of severe AKI. These complications are life threatening and are causes of mortality in severe AKI. Unfortunately, logistics of planning PD as crucial intervention in children with AKI are fraught with many hitches where the expertise exists. These range from non-availability of consumables (especially the dialysis fluids and catheters), high cost of these consumables, late presentation to health facilities, and acceptability of PD by parents/care-givers. The most important of these are non-availability and high cost of PD consumables. Attempts have been made to improvise some of these unavailable and expensive consumables by locally constituting dialysis fluids using commonly available intravenous fluids and adapting nasogastric tubes, urethral catheters, chest drainage tubes and very recently double lumen haemodialysis catheter for use as PD catheters. ${ }^{3-8}$ From the preceding, PD remains the most accessible and viable option for dialysis management of AKI in paediatric patients.

Very few studies on acute PD in children have emanated from the sub-Saharan Africa at large, ${ }^{3,11,12}$ and in Nigeria specifically. 4, 5,8-10 This is due to deficiency in technical know-how, nonavailability of PD materials and more importantly, cost of PD. There are few studies from Southern region of the country and a case report on PD with improvised dialysates on a paediatric patient in Kano, ${ }^{4}$ there is no documented study on acute PD outcome in paediatric population in the North-western Nigeria. This study is an attempt to share our experience as well as bring to forefront some of the challenges facing widespread use of PD in management of AKI in children in Sokoto, Northwestern Nigeria.

\section{Subjects, materials and methods}

The study was carried out at the Paediatric Department of Usmanu Danfodiyo University Teaching Hospital (UDUTH), Sokoto State, North-western Nigeria. This is a tertiary health facility located in Sokoto metropolis, the Sokoto State capital. The hospital serves as a referral centre for more than 10 million people of the States of Sokoto, Zamfara, Kebbi and Niger as well as neighbouring Niger, Chad and Benin Republics in the West African sub-region.

This was a retrospective and descriptive study of all patients admitted into the EPU who had PD done for AKI irrespective of the cause. The study period spanned between $1^{\text {st }}$ of July 2007 to $31^{\text {st }}$ of June, 2019 during which 12 patients received PD for AKI. One patient was excluded from this study due to loss of case file.

All available case files of study patients who had PD for AKI were retrieved and data analysed. These data included sociodemography including social class stratification according to Oyedeji, ${ }^{13}$ causes of AKI, levels at presentation of serum elec- 
trolytes $\left(\mathrm{Na}^{+}, \mathrm{K}^{+}\right.$, and $\left.\mathrm{HCO}_{3}^{-}\right)$, urea and creatinine and at discharge, indications for dialysis, type of dialysates used and duration of PD. Outcome include either discharge due to recovery, against medical advice or death.

PD was done manually in all patients. Only 3 of the patients could afford commercially prepared dialysates (stay.safe ${ }^{\circledR}$ continuous ambulatory PD with $1.5 \%$ Glucose produced by Fresenius Medical Care, Bad Homburg, Germany) sourced from Lagos, Nigeria. Other 8 patients had manual PD done using Ringer's Lactate solution made up to either $1.5 \%$ or $2.5 \%$ dextrose solution using Obiangwu et $a l^{4}$ method (except that Sodium bicarbonate solution was not used in all patients) depending on the hydration status of the patient. Heparin $500 \mathrm{IU}$ and Cefotaxime $250 \mathrm{mg}$ were added to each litre of dialysates. This is to prevent blood from catheter insertion from clotting intraperitoneal. Intravenous cephalosporin was optional and it is to prevent peritonitis. Nasogastric tube (with improvised multiple fenestrations) was used only once while disposable paediatric size semi rigid PD catheters Romsons ${ }^{\circledR}$ Peritoneal dialysis catheter set (Romsons Scientific \&Surgical Industries Pvt. Ltd, Nunhai, Agra, Uttar Pradesh, 282006, India), Potex ${ }^{\circledR}$ Blunt Tip Trocar Catheter Soft size 10F (Smiths Medical International Ltd, Hythe, Kent, CT21, 6JL, UK) and Portex ${ }^{\circledR}$ Seldinger Chest drainage Kit size $12 \mathrm{~F}$ (Smiths Medical International Ltd, Hythe, Kent, CT21, 6JL, UK) were used under aseptic condition at various times as available.

The peritoneal access device (any of the above-mentioned devices) was introduced percutaneously $2 \mathrm{~cm}$ below the umbilicus with a trocar after making a midline incision under local anaesthesia. The catheters were secured using pursestring suture which helped to prevent dislodgement, slip-out and minimize leakage. Bladder catheterization was done prior to peritoneal catheterization to ensure an empty bladder as well as monitor urine production and output. Catheters were inserted by authors.

Indwelling volume was gradually increased from $20 \mathrm{mls} / \mathrm{kg}$ to $40 \mathrm{mls} / \mathrm{kg}$ with indwelling time ranging from 30 minutes to 180minutes (indwelling time prolonged during the nights). Each patient had average of 6 to 8 sessions during the day and 4 to 6 sessions during the night. Urine bag was improvised as a drain set with the use of three-way tap, Soluset ${ }^{\circledR}$ was used where affordable to ensure exact dialysates volume was infused into the peritoneal cavity. Records of PD events i.e number of cycles, indwelling volumes, indwelling time, drainage time, vital signs were documented in improvised PD procedure sheet for all patients. Dialysis was discontinued with commencement of adequate urine production, correction of electrolyte derangement, complication of PD, parents' withdrawal of consent or death of patient.

Demographic and baseline clinical data were reported as means and standard deviations, medians or proportions as appropriate. The software application Statistical Package for the Social Sciences (version 20: SPSS, Chicago, IL, USA) was used for statistical analyses.

\section{Results}

There were 11 children that had PD during the study period with male preponderance of $8(72.7 \%)$ and male to female ratio of 2.7:1. Their ages ranged between 5months and 12 years as depicted in Table 1 with mean age of $4.8 \pm 3$ years and $54.5 \%$ were aged less than 5 years. Two $(18.2 \%)$ belonged to social class I, $1(9.1 \%)$ social class IV and the rest
(72.7\%) belonged to social class $\mathrm{V}$ as shown in Table 1. Median serum urea and Creatinine levels prior to commencement of PD were $23.8 \pm 7$ and $9.8 \pm 2.4$ respectively.

TABLE 1: Demography, causes of acute kidney injury and outcome of peritoneal dialysis for subjects

\begin{tabular}{lll}
\hline & Total & Surviv ors \\
& Variables (n) & n (\%) \\
& & \\
\hline Age & & \\
$\quad<1$ Year & 1 & $1(100.0)$ \\
$1-<5$ Years & 5 & $5(100.0)$ \\
$5-12$ Years & 5 & $2(40.0)$ \\
$\quad$ Sex & & \\
Male & 8 & $5(62.5)$ \\
Female & 3 & $3(100.0)$ \\
\hline Social classification & & \\
I & 2 & $18.2(100.0)$ \\
II & 0 & 0 \\
III & 0 & 0 \\
IV & 1 & $9.1(100.0)$ \\
V & 8 & $72.7(62.7)$ \\
\hline Causes of AKI & & \\
Acute glomerulonephritis (AGN) & 5 & $2(40.0)$ \\
Acute tubular necrosis (from diarrhoea) & 4 & $4(100.0)$ \\
Obstructive Nephropathies & 2 & $2(100.0)$ \\
\hline
\end{tabular}

Causes of AKI necessitating dialysis included primary kidney disease (acute glomerulonephritis) in $5(45.4 \%)$ cases, acute tubular necrosis complicating severe dehydration from diarrhoeal disease in $4(36.4 \%)$ cases and $2(18.2 \%)$ cases of obstructive nephropathies. This is as represented in Table 1.

All patients had multiple indications for PD. Azotaemia and oliguria/anuria were present in all $(100 \%)$ patients, electrolyte derangements in form of severe hyperkalaemia and severe metabolic acidosis were present in 7(63.6\%) and 6(54.5\%) children respectively while fluid retention was present in 3 $(27.3 \%)$ children as indications for dialysis (Table 2 ).

Table 2: Indications for dialysis, complications of peritoneal dialysis (PD) and survival data for subjects

\begin{tabular}{lll}
\hline & Patients & \\
\hline \multicolumn{1}{c}{ Total } & & Survivors \\
& Variable (n) & [n (\%)] \\
\hline Indications for dialysis & & \\
Azotaemia & 11 & $8(72.7)$ \\
Oliguria/Anuri a & 11 & $8(72.7)$ \\
Hyperkalaemia & 7 & $4(57.1)$ \\
Metabolic acidosis & 6 & $3(50.0)$ \\
Fluid retention & 3 & $2(66.7)$ \\
Uraemic encephalopathy & 2 & $0(0)$ \\
& & \\
Complications of PD & & $3(50.0)$ \\
Peri-catheter leakage & 6 & $1(33.3)$ \\
Catheter obstruction & 3 & $2(100.0)$ \\
Exit wound infection & 2 & $0(0)$ \\
Peritonitis & 1 &
\end{tabular}

One (9.1\%) child each had Portex ${ }^{\circledR}$ Seldinger Chest drainage kit size $12 \mathrm{~F}$ and nasogastric tube size 10 improvised as peritoneal catheter while the rest $9(81.8 \%)$ children had Romsons ${ }^{\circledR}$ Peritoneal dialysis catheter set or Potex ${ }^{\circledR}$ Blunt Tip Trocar 
Catheter Soft size 10F inserted depending on which type was available at presentation.

Only $3(27.3 \%)$ of the children had standard commercial peritoneal dialysis fluid (one of these completed PD sessions with improvised dialysates) while the remaining 8 (72.7\%) had improvised dialysates as described by Obiagwu et $\mathrm{al}^{4}$ without addition of $8.4 \%$ sodium bicarbonate solution. PD procedure lasted 3 to 17 days with median duration of $8.1 \pm 4.4$ days and median number of sessions being $55 \pm 17.8$. Catheter malfunction in form of peri-catheter leakages and outflow blockage was the commonest complication occurring in 9 $(81.8 \%)$ (One of them warranting recurrent manipulation and eventual replacement of PD catheter) while exit wound infection occurred in 2 cases $(18.2 \%)$ and peritonitis complicated only $1(9.1 \%)$ of the cases.

Of the 11 children that underwent acute PD, 7 (63.3\%) were discharged home with complete resolution of indications for PD and normalization of renal function and 1 (9.1\%) patient left against medical advice. Median duration of stay on admission was $22.9 \pm 10.9$ days. We recorded 3 (27.2\%) deaths, one of which was complicated by acute bacterial peritonitis. Two of the 3 mortalities recorded presented in altered consciousness (uraemic encephalopathy) and all had AGN. All had improvised PD fluids. In all, $60 \%$ of all AGN who had acute PD died while 1 also left against medical advice. However, all other children who had acute PD secondary to AKI from acute tubular necrosis from severe dehydration of diarrhoeal disease and obstructive nephropathy survived.

\section{Discussion}

Peritoneal dialysis was first done in our facility in 2007, though our Centre has a well-established Haemodialysis centre that has been catering for children weighing $30 \mathrm{~kg}$ or more whose parents/caregivers that could afford financial cost. The index case was a 4-year-old boy referred from a peripheral health facility on account of anuria of 2 days duration. Essentially, he had suffered ATN as a complication of severe dehydration from acute diarrhoeal disease. He had sessions of acute PD with standard commercial dialysates over 9 days and was discharged home without any residual renal dysfunctions after 16 days on admission. Since this first PD, we have had a number of AKI warranting PD but only additional 11 had PD done. This was initially as result of cost of PD materials especially the dialysis fluids until in the last 5 years when we perfected the use of improvised dialysis fluids using Ringer's lactate fluid and other items as documented by Obiagwu et $\mathrm{al}^{4}$ in Kano.

Our experience in the last 5 years truly demonstrated that PD is feasible for every child needing the procedure for management of severe AKI. We had 6 cases of AKI who had PD management in the last 5 years though altogether, we had a total of 12 children who underwent PD since 2007 till date. Twelve cases of manual acute PD over 11 years is similar to that of Anochie et $\mathrm{al}^{10}$ in Port Harcourt with 21 patients over 19 years but a far less than those of Ademola et $\mathrm{al}^{5}$, Ezesobor et $\mathrm{al}^{6}$, Solarin et $\mathrm{al}^{9}$ and Adedoyin et $\mathrm{al}^{7}$ in Ibadan, Lagos and Ilorin respectively. These are centres with well-established Paediatric Nephrology units unlike ours. More so, Ibadan and Lagos are far bigger than Sokoto in term of population with probably more parents and caregivers rich enough to afford the procedure. It is noteworthy that less than $30 \%$ of patients needing PD for optimal management of their AKI were able to access the services due to cost in our centre. This is logical because cost was borne out of pocket in all patients as National Health Insurance Scheme (NHIS) does not cover PD procedure as part of management for AKI.

The most common underlying cause of AKI in our study cohort was AGN, followed by acute tubular necrosis complicating severe dehydration from acute diarrhoeal disease and obstructive nephropathy. Gnenefoly Diarrassouba ${ }^{12}$ had similar finding in Abidjan, Côte d'Ivoire but at variance with other Nigerian studies where sepsis and Malaria were the commonest underlying causes. Unlike these other studies, there were no neonates among our patients, the youngest being a 5-month-old female infant who presented with anuria of a day duration following acute diarrhoeal disease but later turned out to be vesical stone which she passed after 48 hours on PD. All our mortalities were from AGN just as reported by Ademola et $\mathrm{al}^{5}$ and Solarin et $\mathrm{al}^{9}$ however our mortality rate for AGN was $60 \%$ whereas they reported $100 \%$. This high mortality rate may not be unconnected with the nature of this primary renal disease as it tends to follow a rapid deterioration of clinical condition despite intervention. More so, late presentation is the order of the day after wasting so much time and funds on alternative medicine.

A number of tubes have been improvised for PD catheter and these include nasogastric tubes, urethra catheters and chest drainage kits. Most of our patients had standard commercial semi-rigid percutaneous PD catheters inserted for the procedure while 2 had guard wire equipped Seldinger chest drainage kit and size $12 \mathrm{~F}$ nasogastric tube improvised respectively. This was the case in most studies done across the country except that of Solarin et $\mathrm{al}^{9}$ in Lagos where Tenckhoff catheters were used in some of their subjects. The semi-rigid PD catheters are more accessible and far cheaper than the gold standard Tenckhoff catheter. With Tenckhoff, the usual problems of outflow obstruction and peri-catheter leakage commonly encountered with other types of catheters are eradicated. This was so because it has wider lumen and numerous fenestrations on the side some length from the tip for improved dialysate flow. Tenckhoff catheters are originally designed for chronic $\mathrm{PD}$ as the process of subcutaneous tunnelling helps to prevent dislodgement, peri-catheter leakage and to some extent, eliminate peritoneal contamination from the exterior which close circuit dialysates flow in place. ${ }^{14,15}$

Until recently, accessibility of PD fluids due to cost has been the rate limiting factor for widespread use of PD in management of AKI in children where expertise was available throughout the country. With Antwi ${ }^{3}$ and Obiagwu ${ }^{4}$ case reports and other acute PD in children studies from centres across the country, good outcome with use of improvised PD fluid has shown that with properly constituted fluids and aseptic precaution, availability of standard commercial PD fluid should no longer be a hindrance to acute PD in children. Apart from Ademola et al study ${ }^{5}$ where standard commercial PD fluids were available due to donation from a Good Samaritan, all other Nigerian studies have tried improvised/constituted fluids with somewhat good outcome. For us, the outcome has been quite very good as we were able to save children that ordinarily would have died from complications of severe AKI.

Azotaemia, oliguria/anuria and severe electrolyte derangements (hyperkalaemia and metabolic acidosis) were our most common indications for acute PD in our review. This is similar to Ademola et al findings in Ibadan ${ }^{5}$, Esezobor et al ${ }^{6}$ Solarin et $\mathrm{al}^{9}$ in Lagos, Anochie and Eke et $\mathrm{al}^{10}$ in Port Harcourt and Gnenefoly Diarrassouba in Abidjan, Côte d'Ivoire ${ }^{12}$ but 
different form Olowu's ${ }^{16}$ findings of severe systemic hypertension and congestive cardiac failure as common indications among his subjects. Severity of primary renal disease as a cause of AKI and very late presentation may be logical reasons for this dissimilarity.

Catheter malfunction in form of peri-catheter leakage and outflow obstruction was the most common complication we observed in our review and this is similar to most of other studies $^{5,6,9,10}$. It has been attributed to use of semi-rigid PD catheters and other improvised tubes as a result of smallness of their luminal diameter compared to the standard Tenckhoff catheter ${ }^{15}$ as well as manual nature of the procedure. This complication is rarely seen with use of cycler machines and surgically placed Tenckhoff catheters. Peritonitis as complication was seen in only $1(9.1 \%)$ of the 11 children we studied and Escherichia coli was isolated despite empirical use of cefotaxime $250 \mathrm{mg} / \mathrm{L}$ in the PD fluid. He had PD for 19 days. We however lost the patient despite aggressive treatment. It is the most feared complication of PD and occurrence increases with duration of $\mathrm{PD}$, use of constituted dialysates and poor observance of aseptic procedure. More so, PD is done manually by the bedside open ward in most centres in the country with difficulty in maintaining aseptic environment. ${ }^{3-9}$ Ours is one of the lowest figures compared to all other Nigerian studies ${ }^{4,5,8-10}$ so far. This may be due to small subjects' number over 12 years though strict aseptic procedure was observed in all these children as precautionary measure against peritonitis. PD was carried out in the open ward but other patients were moved out during most of the procedure.

Our mortality profile of $27.2 \%$ is similar to Anochie and Eke's $^{10} 22.2 \%$ among 21 children, Ademola et al rate of $30 \%$ among 27 subjects $^{5}$, Solarin et al ${ }^{9}$ rate of $29 \%$ mortality among 17 children but lower than Esezobor et $\mathrm{al}^{6}$ reported rate of 41.2\% among 17 children and Adedoyin et al's ${ }^{7} 45.5 \%$ among 11 subjects. These figures are far higher than $10 \%$ reported in Western countries ${ }^{14}$ and it is expected due to the fact that standard consumables are easily accessible with the procedure being fully automated. This variation in mortality profile among Nigerian studies may be related to subjects' age difference, severity of underlying causes of AKI, differential availability of PD consumables and very late presentation in some centres. Nigerian figures are comparable with Gnenefoly Diarrassouba rate of $36.4 \%$ among 22 children in Abidjan, Côte d'Ivoire $^{13}$ in the same West African sub-region as well Salim's 32.9\% among 82 children in Iraq. ${ }^{17}$

Looking beyond these high mortality figures from all over the country, it can be concluded that acute PD is achievable for paediatric patients needing the procedure with outlook for good outcome. This can be attained by cautious improvision of necessary consumables and meticulous observation of aseptic procedure as much as possible considering the nature of our environment.
The small sample size of this research as with most Nigerian studies reviewed is its major limitation however; being able to save some of our children with severe AKI by successfully carrying out acute PD with the use of improvised/constituted fluids and catheters is gratifying. More so, we believe that our results in this study will encourage other centres with technical knowhow (yet to attempt acute PD for children with severe $\mathrm{AKI}$ in need of PD) to break the ice.

\section{Conflict of interest and financial support for this study}

None

\section{References}

1. Cullis B, Abdelraheem M, Abrahams G, Balbi A, Cruz D, Frishberg Y et al. ISPD guidelines: Peritoneal Dialysis for acute kidney injury. Perit Dial Int 2014;34(5):494-517

2. Walters S, Porter C, Brophy PD. Dialysis and pediatric acute kidney injury: choice of renal support modality. Pediatr Nephrol 2009; 24:37-48

3. Antwi S. Peritoneal dialysis using improvised PD catheter and selfconstituted dialysis solution. Proceedings at the fifteenth congress of the International Pediatric Nephrology Association New York, 2010. Available from http://dspace.knust.edu.gh/bitstream/123456789/569/1/PD\%20 in\%20KATH.doc.pdf, accessed 23/ 08/2019

4. Obiagwu PN, Gwarzo G, Akhiwu H, Wada A. Managing acute kidney injury in a child with improvised peritoneal dialysis in Kano, Nigeria. Niger J Basic Clin Sci 2012;9(2):84-86

5. Ademola AD, Asinobi AO, Ogunkunle OO, Yusuf BN, Ojo OE. Peritoneal Dialysis in childhood Acute Kidney Injury: Experience in Southwest Nigeria. Perit Dial Int 2012; 32(3): 267-72

6. Esezobor CI, Ladapo TA, Lesi FE. Peritoneal Dialysis for children with Acute Kidney Injury in Lagos, Nigeria: Experience with Adaptation. Perit Dial Int 2014;34(5):534-38

7. Adedoyin OT, Ibrahim OR, Abdurrahman LO, Nasir AA, Olorunshola BO, Abdulazeez TA et al. Peritoneal dialysis in children with acute kidney injury: the Ilorin experience. Afr J Paed Nephrol 2015;2: 72-76

8. Okonkwo NC, Ijeoma S, Chapp-Jumbo AU, Eke FU. Improvised peritoneal dialysis on a 5 year old girl: Experience with double lumen haemodialysis catheter In South East Nigeria. Afr J Paed Nephrol 2017; 4: $49-56$

9. Solarin AU, Aremu EO, Gbelee HO, Salisu M and Animashaun BA. Acute Peritoneal Dialysis Experience in a Public Tertiary Hospital in Nigeria: Challenges and Limitations of a Resource Poor Nation. Trop J Nephrol 2017; 12(2): 45 - 52

10. Anochie IC, Eke FU. Paediatric acute peritoneal dialysis in southern Nigeria. Postgrad Med J 2006; 82:228-30.

11. Fedrick F, Valentine G. Improvised peritoneal dialysis in an 18-month-old child with severe acute malnutrition (Kwashiokor) and acute kidney injury. Journal of medical case reports 2013; 7:168- 72

12. Diarrassouba G, Adonis-Koffy L, Niamien E, Yaokreh JB, Coulibaly PA. Acute Peritoneal Dialysis in African Paediatric Area Experience of paediatric Nephrology unit of Yopougon University Hospital Abijan, Cote d'Ivoire. Blood Purif 2015; 39: 141-44.

13. Oyedeji GA. Socio-economic and cultural background of hospitalized children in Ilesa. Niger J Paediatr 1985;12:111-17

14. Flynn JT, Kershaw DB, Smoyer WE, Brophy PD, McBryde KD, Bunchman TE. Peritoneal dialysis for management of pediatric acute renal failure. Perit Dial Int 2001; 21:390-94

15. Wong SN, Geary DF. Comparison of temporary and permanent catheters for acute peritoneal dialysis. arch Dis Child 1988; 63:827-31

16. Olowu WA, Adelusola KA. Paediatric acute renal failure in southwestern Nigeria. Kidney International 2004; 66(4):1541-48.

17. Abdullah, SZ. Peritoneal dialysis in children with acute renal failure in Ibn Al-Balady Hospital. Iraqi Postgrad Med J 2015; 14(1):1-6 